\title{
A study of HIV positive undocumented African migrants' access to health services in the UK
}

\author{
James Whyte IV*, Maria D. Whyte, Sabrina Dickey \\ Florida State University, Tallahassee, Florida, United States
}

Received: October 4, 2017

DOI: $10.5430 /$ jnep.v9n1p122
Accepted: June 21, 2018

URL: https://doi.org/10.5430/jnep.v9n1p122

\begin{abstract}
Newly immigrated persons, whatever their origin, tend to fall in the lower socioeconomic levels. In fact, failure of an asylum application renders one destitute in a large proportion of cases, often resulting in a profound lack of access to basic necessities. With over a third of HIV positive failed asylum seekers reporting no income, and the remainder reporting highly limited resources, poverty is a reality for the vast majority. The purpose of the study was to determine the basic social processes that guide HIV positive undocumented migrant's efforts to gain health services in the UK. The study used the Grounded Theory Approach. Theoretical saturation occurred after 16 participants were included in the study. The data included reflections of the prominent factors related to the establishment of a safe and productive life and the ability of individuals to remain within the UK. The data reflected heavily upon the ability of migrants to enter the medical care system during their asylum period, and on an emerging pattern of service denial after loss on immigration appeal, which often resulted in a discontinuation of medical therapies. This inevitably was associated with a pattern of decline and inability to fundamental needs. The findings of this study are notable in that they have demonstrated sequence of events along a timeline related to the interaction between the asylum process and access to health related services. The results reflect that African migrants maintain a degree of formal access to health services during the period that they possess legal access to services and informal access after the failure of their asylum claim.
\end{abstract}

Key Words: HIV positive, African migrants, Grounded theory approach

\section{INTRODUCTION}

The purpose of this paper is to examine the efforts to gain access to health services among HIV positive undocumented African migrants to the United Kingdom (UK). While the government of the UK has recognized limits to their ability to quantify and track the undocumented population as early as 2001, their efforts to date have resulted in widely varying representations of the undocumented population. ${ }^{[1]}$ The most recent estimates indicate that there are a total of $618,000 \mathrm{mi}-$ grants who lack legal status within the UK. ${ }^{[2]}$ Other studies have placed the number of undocumented migrants within the UK in the range of 525,000 to $950,000 .^{[2]}$ More than 442,000 are thought to dwell in the London metropolitan area. While the government continues to fail to document the degree of the undocumented population, the Home Office has documented that nearly 1.5 million Africans currently dwell in the UK, with the majority originating from Sub-Saharan Africa. ${ }^{[3]}$ There is no available estimation of the total number of undocumented migrants from Africa, despite the fact that most overstay legitimate visas.

Newly immigrated persons, whatever their origin, tend to fall in the lower levels with regards to socioeconomic status. In fact, failure of an asylum application renders a newly immigrated person destitute in a large proportion of cases, often resulting in a profound lack of access to basic necessities including health services. ${ }^{[2]}$ Even in cases where African States.

*Correspondence: James Whyte IV; Email: jwhyte@fsucon.org; Address: College of Nursing, Florida State University, Tallahassee, Florida, United 
migrants enter the UK legally, they often face considerable difficulty in their quest to gain legal employment due to barriers inherent to the system that grants work permits. ${ }^{[4]}$ With over a third of HIV positive failed asylum seekers reporting no income, and the remainder reporting highly limited resources, poverty is a reality for the vast majority. ${ }^{[5]}$ Further complicating the issue of poverty is the profound destitution associated with the failed asylum application. ${ }^{[6]}$ That is, loss on appeal generally results in loss of eligibility for social care benefits. ${ }^{[6-8]}$ The combination of poverty that pre-exists entry to the UK, difficulty in gaining legal employment, and deprivation of social assistance after the failure on asylum requests results in significant destitution for HIV positive African migrants to the UK. The ramifications of lacking medical care are significant, not only as a threat to the individual, but also as a public health threat to the population in general.

The general process of seeking healthcare in the UK focuses on a primary care model, with the initial access point being the General Practitioner (GP). It is through the GP that access to a broad array of services is made available to those who enjoy legal status. Additionally, care for HIV positive people is provided at the GU Medicine Clinics. These clinics, provide specialty services such as antiretroviral therapy and HIV related testing and health services. Once one loses legal status, they are no longer eligible to gain these services, and thus, are left to seek assistance from the limited number of NGOs who provide services to undocumented migrants. This places undocumented migrants in the position that they cannot receive normal follow up care, but are eligible for care during life threatening episodes.

The specific aims of this paper are:

(1) To examine the basic social processes that guide African migrants living with HIV/AIDS efforts to access medical care within the UK.

(2) To examine cases where health services are gained and determine the most common modalities wherein African migrants living with HIV/AIDS gain access to health services.

\section{Background and significance}

There are few studies that reflect on usage patterns and demographics associated with undocumented migrants' efforts to gain health services in the UK. Chauvin et al. (2008) completed a study of 11 European countries that included data reflecting a sample of undocumented migrants in the London area. ${ }^{[9]}$ The data from this study reflected a population that was comprised of $46.3 \%$ women and $53.7 \%$ men, with a mean age of 37 years. The country of origin of those included in the sample included $36.1 \%$ from Africa, with the vast ma-

Published by Sciedu Press jority originating in Sub Saharan Africa. The majority of persons contained in the UK sample had been present in the country for 5 years (25.9\%) with a significant number $(25 \%)$ having been present for 2-3 years. These statistics reflect a population comprised primarily of failed asylum seekers. The majority $(69 \%)$ of undocumented migrants had been subjected to violence in the past. Chronic medical problems were reported in $25.9 \%$ of cases, with $75 \%$ reporting having delayed treatment for acute of chronic medical problems. In total, $69.7 \%$ reported no current access to health services.

The most significant change in healthcare access regarding the newly immigrated occurred in 2004, when free access to care for visitors was strictly prohibited. ${ }^{[10]}$ Subsequently, healthcare providers began to make determinations of eligibility for services, often placing them at odds with both established human rights standards and their own professional ethics. ${ }^{[10]}$ The stated reason for restricting this care was based upon financial concerns related to the concept of health tourism. ${ }^{[11]}$ To date, there has been no empirical evidence that links the cost attributed to health tourism and the savings associated with restriction of service. ${ }^{[11]}$ The denial of services to undocumented migrants, and the degree of poverty seen amongst undocumented African migrants has become a source of contention amongst many involved in the healthcare debate in Europe. ${ }^{[10]}$ While precise causes have not been identified, there have been broad inconsistencies in the implementation of procedures designed to regulate undocumented migrants access to services. ${ }^{[12]}$ Even in cases where care is authorized, for instance, during appeal of denial on an initial asylum application, accessing care can be very difficult due to the myriad administrative requirements associated with accessing services. ${ }^{[13]}$ The result of such practices is the lack of uniformity in charging procedures, which serves to influence migrants in need to refrain from seeking care. ${ }^{[13]}$

The primary effect of access to care limitations in African migrants to the UK has been associated with delays in presentation for HIV related services. Studies have shown that $80 \%$ of migrants experience difficulty in maintaining good health, particularly in the ill or disabled, as is seen in those living with HIV/AIDS. ${ }^{[14]}$ These delays result in the lack of or inadequate treatment, and thus, increase the odds of immune system degradation. Burns et al. investigated the causes of poor patterns of service utilization amongst Africans. ${ }^{[15]}$ The findings of this study support the notion that access to specialty care, combined with GPs inadequacies in addressing HIV disease is problematic. Additionally, the authors cited factors such as cultural insensitivity and failure to coordinate care with social support organizations as problematic. ${ }^{[15]}$ The current study is supported by the notion that individuals fail 
to gain long-term care in the GU Medicine clinic system and thus fall to the care of the GPs who are ill equipped to care for persons who are HIV positive. Boyd et al further supports these findings, corroborating the fact that later presentation for testing decreases progression to care. ${ }^{[16]}$ Finally, Chadborn et al were the first researchers to show that short-term mortality was influenced negatively by this pattern of late presentation. ${ }^{[17]}$

\section{MethodS}

The Grounded Theory Method (GTM) was used throughout the conduct of this study, due to the method's ability to integrate data and offer a structured method through which data may be analyzed and interpreted. Since this study involved contact with individuals vested in the issue at hand, in their naturalistic environment, this was an ideal method through which to conduct a study of this nature. Glaser and Strauss developed the GTM in 1967. ${ }^{[18]}$ Due to its focus on giving structure and extracting theory from data that is inherently unstructured, and then extracting theory from the data, this method is fundamentally inductive. The strength of the GTM lies in the fact that the theory that it provides a practice and accurate explanation of the phenomenon of interest. ${ }^{[19]}$ The strength of the GTM lies largely in the practical way that it records and organizes data regarding human social interactions. ${ }^{[20]}$ Key to the pragmatic, clear and structured approach associated with the GTM is its ability to derive theory from emerging social patterns that are present in the data, while capturing their essence in a way that clearly explains the relationships between key variables. ${ }^{[21]}$

One of the primary challenges of the study was to gain adequate data that reflected the broad range of experiences within the HIV positive African community. Due to their experience with multiple cases involving HIV positive migrants, social care workers at agencies that provide services to undocumented African migrants were selected. Data was collected from workers at 16 Non-Governmental Organizations (NGOs) that offer assistance to undocumented migrants. Specifically, NGO workers selected at the various sites included in the study were those engaged in service coordination and case management. These workers were selected based upon their extensive contact with clientele, and associated familiarity with the experiences of undocumented African migrants. A total of 24 workers were included in the interviews, with 20/24 workers who were African migrants themselves. The majority (17) workers were assigned as "African services workers", while the remainder were healthcare providers of case management professionals. Demographics indicate a mean age of 36.24 (SD 6.77) years, with a mean number of years work experience with this population of 11.02 (SD 3.72) years. In total 16 of 24 workers were men, with the remainder identifying themselves as women. Overall, the sample reflected a mature, racially and ethnically diverse and highly experienced group.

Detailed descriptions of the agencies included in the study are contained in Table 1. These agencies do not provide medical care. Each of the agencies are unique but have in common case management services, educational services aimed at potentiating participation in care, and social assistance programs. Each of the agencies was visited by the researcher in-person. It is important to note that all told, there were more than 60 agencies across the country that dealt with African Migrants Living with HIV. The study was meant to focus on a national representation of the phenomenon. The study focused on three major areas: London, The Midlands (Liverpool, Birmingham and Wolverhampton) and Liverpool. Accordingly, the major service provides in these areas were contacted, and those who volunteered to participate were included.

Interviews were conducted in-person, in the agencies included in the study. All interviews were tape-recorded. Tapes were then transcribed. A second research worker then reviewed and verified the accuracy of the transcriptions prior to any coding activities. The transcripts were then coded independently by two research team-members. Following this coding, comparisons were made and a highly experienced third researcher, who resolved any conflicts throughout the codes. These measures were undertaken to ensure the veracity of the analysis.

\section{RESUlts}

The results of the study will be presented according to themes that arose from the data during continuous comparative analysis. These themes will be presented according to gerunds, which is a common practice when using the GTM. These represent the Basic Social Processes experienced by undocumented immigrants as they establish their lives in the UK and strive to access medical care.

\subsection{Seeking access to needed health services}

During this section, the efforts of persons who initially entered with some form of legal status, but later lose legal status based upon failure to gain asylum will be explored. Further complicating the issue is the fact that, for the newly arrived, challenges during the process of gaining health services was evident within the data. During the analysis of this element of the data several sub-themes arose: 1) Failing to secure care due to socio-cultural factors, 2) Seeking initial access to care through the general practitioner and 3) Seeking HIV specific care via the consultants.

ISSN 1925-4040 E-ISSN 1925-4059 
Table 1. Participating agencies in UK

\begin{tabular}{|c|c|c|}
\hline Agency Location & Primary Population Served & Agency Activities \\
\hline London & $\begin{array}{l}\text { 1. People living with HIV/AIDS } \\
\text { 2. Populations at risk of contracting HIV/AIDS }\end{array}$ & $\begin{array}{l}\text { 1. Individual and community educational Services. } \\
\text { 2. The provision of educational materials. } \\
\text { 3. HIV and STD prevention services. } \\
\text { 4. Case management services. } \\
\text { 5. Legal and immigration assistance. } \\
\text { 6. Individual counseling. } \\
\text { 7. HIV and STD testing. }\end{array}$ \\
\hline London & African populations & $\begin{array}{l}\text { 1. HIV and STD prevention services. } \\
\text { 2. Case management services. } \\
\text { 3. Legal and immigration assistance. } \\
\text { 4. Individual counseling. }\end{array}$ \\
\hline London & $\begin{array}{l}\text { 1. People living with HIV/AIDS } \\
\text { 2. Populations at risk of contracting HIV/AIDS } \\
\text { 3. Each of the above are in the context of the evangelical church } \\
\text { community in the city }\end{array}$ & $\begin{array}{l}\text { 1. Coordination of social care needs. This includes childcare, social care and educational assistance. } \\
\text { 2. Home care and maintenance assistance. } \\
\text { 3. Assistance with daily needs such as food, shopping and transportation. } \\
\text { 4. The provision of educational materials. } \\
\text { 5. HIV and STD prevention services. } \\
\text { 6. Legal and immigration assistance. }\end{array}$ \\
\hline London & $\begin{array}{l}\text { People within and outside of the UK with difficulty accessing } \\
\text { medical care. }\end{array}$ & $\begin{array}{l}\text { 1. Public advocacy. } \\
\text { 2. Political campaigns supporting groups at risk related to their lack of access to medical care. } \\
\text { 3. Legal counseling. } \\
\text { 4. Case management services (UK only). } \\
\text { 5. Education regarding methods through which to gain healthcare access. }\end{array}$ \\
\hline London & $\begin{array}{l}\text { People being held inside of or those who have been released from } \\
\text { immigration detention. }\end{array}$ & $\begin{array}{l}\text { 1. Public advocacy. } \\
\text { 2. Political campaigns supporting groups at risk related to their lack of access to medical care. } \\
\text { 3. Legal counseling. } \\
\text { 4. The documentation of medical conditions to provide support for asylum applications. } \\
\text { 5. The provision of medical consultation and support to those being held in immigration detention. }\end{array}$ \\
\hline London & Asylum seekers and undocumented migrants with health needs. & \\
\hline London & $\begin{array}{l}\text { HIV positive individuals with immigration concerns including } \\
\text { those in detention. }\end{array}$ & $\begin{array}{l}\text { 1. Specialist consultation regarding HIV/AIDS care for people being held in immigration detention } \\
\text { and for immigrants with such needs. } \\
\text { 2. Public advocacy. } \\
\text { 3. Political campaigns. }\end{array}$ \\
\hline London & Immigrant populations who lack access to the NHS. & $\begin{array}{l}\text { 1. Direct medical care. } \\
\text { 2. Case management services. } \\
\text { 3. Referral and coordination of immigration related legal services. }\end{array}$ \\
\hline Manchester & $\begin{array}{l}\text { 1. People living with HIV/AIDS } \\
\text { 2. Populations at risk of contracting HIV/AIDS }\end{array}$ & $\begin{array}{l}\text { 1. Individual and community educational Services. } \\
\text { 2. The provision of educational materials. } \\
\text { 3. HIV and STD prevention services. } \\
\text { 4. Case management services. } \\
\text { 5. Legal and immigration assistance. } \\
\text { 6. Individual counseling. } \\
\text { 7. HIV and STD testing. }\end{array}$ \\
\hline Wolverhampton & $\begin{array}{l}\text { 1. People living with HIV/AIDS } \\
\text { 2. Populations at risk of contracting HIV/AIDS }\end{array}$ & $\begin{array}{l}\text { 1. Individual and community educational Services. } \\
\text { 2. The provision of educational materials. } \\
\text { 3. HIV and STD prevention services. } \\
\text { 4. Case management services. } \\
\text { 5. Legal and immigration assistance. } \\
\text { 6. Individual counseling. } \\
\text { 7. HIV and STD testing. }\end{array}$ \\
\hline Birmingham & $\begin{array}{l}\text { People at risk of or who have been infected with sexually } \\
\text { transmitted diseases. }\end{array}$ & $\begin{array}{l}\text { 1. Individual and community educational Services. } \\
\text { 2. The provision of educational materials. } \\
\text { 3. HIV and STD prevention services. } \\
\text { 4. Individual counseling. } \\
\text { 5. HIV and STD testing. }\end{array}$ \\
\hline Birmingham & $\begin{array}{l}\text { 1. People living with HIV/AIDS } \\
\text { 2. Populations at risk of contracting HIV/AIDS }\end{array}$ & $\begin{array}{l}\text { 1. Individual and community educational Services. } \\
\text { 2. The provision of educational materials. } \\
\text { 3. HIV and STD prevention services. } \\
\text { 4. Case management services. } \\
\text { 5. Legal and immigration assistance. } \\
\text { 6. Individual counseling. } \\
\text { 7. HIV and STD testing. }\end{array}$ \\
\hline Liverpool & People living with HIV/AIDS & $\begin{array}{l}\text { 1. Individual and community educational Services. } \\
\text { 2. The provision of educational materials. } \\
\text { 3. Case management services. } \\
\text { 4. Legal and immigration assistance. } \\
\text { 5. Individual counseling. } \\
\text { 6. Massage, Acupuncture and physiotherapy. } \\
\text { 7. Home maintenance and gardening assistance. }\end{array}$ \\
\hline Liverpool & $\begin{array}{l}\text { 1. People living with HIV/AIDS } \\
\text { 2. Populations at risk of contracting HIV/AIDS }\end{array}$ & $\begin{array}{l}\text { 1. Individual and community educational Services. } \\
\text { 2. The provision of educational materials. } \\
\text { 3. HIV and STD prevention services. } \\
\text { 4. Case management services. } \\
\text { 5. Legal and immigration assistance. } \\
\text { 6. Individual counseling. }\end{array}$ \\
\hline Liverpool & People living with HIV/AIDS & $\begin{array}{l}\text { 1. Individual and community educational Services. } \\
\text { 2. The provision of educational materials. } \\
\text { 3. HIV and STD prevention services. } \\
\text { 4. Case management services. } \\
\text { 5. Legal and immigration assistance. } \\
\text { 6. Individual counseling. } \\
\text { 7. Massage, Acupuncture and physiotherapy. } \\
\text { 8. The provision of meals at the agency and in the homes of those unable to care for themselves. } \\
\text { 9. The provision of home care assistance. }\end{array}$ \\
\hline Liverpool & $\begin{array}{l}\text { 1. People living with HIV/AIDS } \\
\text { 2. Populations at risk of contracting HIV/AIDS }\end{array}$ & $\begin{array}{l}\text { 1. Individual and community educational Services. } \\
\text { 2. The provision of educational materials. } \\
\text { 3. HIV and STD prevention services. } \\
\text { 4. Case management services. } \\
\text { 5. Legal and immigration assistance. } \\
\text { 6. Individual counseling. }\end{array}$ \\
\hline
\end{tabular}




\subsubsection{Failing to secure care due to socio-cultural factors}

The initial thrust of this study involved a search for institutional and governmental limitations. The data, however, yielded the presence of significant factors that likely play a role in establishing de facto limitations to care seeking behaviors amongst African migrants beyond institutional and governmental limitations. Many participants identified the presence of cultural trends within the African community that result in the stigmatization of those who are HIV positive. Thus, these individuals often avoid accessing care, HIV testing services and even treatment, a trend that is reflected in the following passage.

For instance, if they are ill or have HIV, they may not know if they are eligible for care or where they might gain care if they are eligible. On top of that, they are bound by things like stigma. Although people know that they have been exposed to HIV most people don't want to test because of the stigma attached to HIV. They don't want to know. You see in Africa it might bring shame on them with their families and here, they might end up feeling as if they were undesirable. (General Practitioner, 17 years experience, serves large African clientele, also involved with an NGO catering to their care.)

\subsubsection{Seeking initial access to care through the general practitioner}

The normal access point to the healthcare system within the UK is the general practitioner. In the care of Africans newly arrived to the country, they gain official access to a general practitioner once that have filed for asylum or established legal status within the country. This represents a significant basic social process in the context of the current study. The relationship between the general practitioner and the individual who has failed to gain legal status will be discussed later in this paper. The issues surrounding initial attempts to access the healthcare system reached theoretical saturation very early during data collection, and are reflected in the following passage.

At some point they are all eligible for care within NHS. Look, you just can't walk here from Africa, right. It's not like the states where a bloke can just pop up on the border. They come on various visas or as refugees and all seem to get a period of time when they can access services. It is interesting to me, in my work that this does not always happen. (interviewer "Please Explain?") Well, they have other priorities, right.
They must work, eat, find somewhere to live, take care of their families. Everything is a challenge to this group, nothing is easy. (Consultant Physician, 20 years experience in HIV/AIDS care.)

\subsubsection{Seeking HIV specific care via the consultants}

Those who present to the general practitioner with HIV or those who are subsequently diagnosed receive referral to the genitourinary medicine clinic. This is the normal site for the provision of HIV related care, and the sole location where antiretroviral therapies can be prescribed. The participants often cited elements of the care afforded to those with legal status, with theoretical saturation having occurred early in the process. This is a crucial point in the basic social processes, and is reflected upon in the following passage.

Let me tell you though, explain to you, so that you understand the way that one gains care for HIV in the UK. One cannot really get HIV treatment, especially medicine form the GP. You can only access it from the hospital, the GUM clinic to be specific. This is the sole site at which they can gain this form of care, which is a considerable problem. You see, the GPs tend not to check eligibility, but the hospitals where these clinics are situated are a different story. They are far more likely to check. During the time that people have application pending, this is generally not a problem. (Case Worker, self identified as living with HIV, 21 years experience in advocacy and social care.)

\subsection{Struggling to maintain access to health and social services after failure during the appeals process}

The previous section related to the fact that the vast majority of individuals entering from African countries initially are able to legally access health related services. The concept represented in this section is central to this thesis, in that it addresses the vital element represented by the majority of Africans who lack legal authorization to remain in the country. The failure of individuals to gain asylum after initial application and upon appeal is catastrophic in the lives of Africans living with HIV/AIDS. During the analysis the following subthemes arose. They were: 1) Gaining basic health services through the general practitioner, and 2) Working to maintain HIV specific services through the consultant.

One factor that was nearly universal reflected upon the perception on the part of the participants that undocumented African migrants experience limitations to their access to healthcare. That is, while the majority of participants spoke 
freely regarding the limitations to healthcare access placed upon undocumented migrants, there was a pervasive feeling communicated by the participants that this was a relatively recent development within the NHS, and is reflected in the following passage.

Over the last two years our work has really centered about access to healthcare. As you know, the NHS has put into place vast limits to gaining services. I would say that this has been unique to the UK. Until 2004 or so no one in the UK would have considered denying service to an individual. (Interviewer "Unique?") Oh yes, now remember, in the US, once could put together some money and go in for an appointment at a fee for service clinic. It is our position that the UK is very unique in that we have a single tiered system, a monopoly if you will. There is nowhere else to go. We suddenly found as part of our work getting people into care. For the first time, around 2005, we began having people who were unable to gain care. So we began to alter our mission, and, and campaign on these issues as this was clearly a growing problem.

\subsubsection{Gaining basic health services through the general practitioner}

Perhaps the most interesting factor was the participant's reflections regarding the level of access to GP clinics experienced by individuals who had lost their legal status through refusal of their asylum applications. The participants who cited this process within their interviews were nearly unanimous regarding their perception that the vast majority of their clients continued to have access to GP based care. Interestingly, the recurring theme in this element of the data was based upon close relationships formed between GPs and their patients along with their concurrent refusal to cease providing them care based upon this relationship was commonly reflected upon, as it is in the following passage.

In terms of healthcare, most GPs in the clinics, they tend to put a blind eye to these issues, and they, the GPs that is, continue to offer them care. I will give you a scenario, maybe something like you see in the USA. You have been looking after this patient and they were an asylum seeker, and you cared for them. And after this five years somehow they have failed to gain asylum. And you know, you see, that you now can't offer them care, but you also know that there is no real link between the GP clinic, or even the GM clinic and the home office, so what do your do?

Published by Sciedu Press
Do you just stop giving them the care, or do you continue to help this person that was your patient. So, as I said, many of the doctors just look the other way. (Consultant Physician, 14 years experience in HIV/AIDS care.)

While this represents a form of access to care, the focus of this project was on individuals from Africa who were also afflicted with HIV/AIDS. During data collection, the participants reflected intensely on the issue of GP versus consultant access and the factors that differentiated these levels of care. There was near unanimous agreement that, while the GPs continued to offer access, they were not able to directly address HIV disease specific care, as reflected in the following passage.

I have two points of view I suppose. One as a consultant, and one as an official with the (agency de-identified). I suppose they are not all too different. As a consultant, I am able to offer the full range of testing and antirets to my patients. I can properly follow their disease progression in every way. The GPs in this area of (area de-identified) are a wonderful bunch of people, and they want to do what is right, but they are severely limited. They do not have the ability to track CD4 counts, viral loads, and certainly don't have access to antirets [antiretrovirals]. (Consultant Physician, 20 years experience in HIV/AIDS care.)

In fact, this was a widely held perception of the participants from a variety of areas.

Here in (location de identified), the GPs are wonderful, and they do their best in most cases. They can't offer care related to HIV or AIDS. This is a very small town, and the other medical services are limited though, and nowadays they are beginning to check. (Case Worker, 12 years experience in HIV/AIDS care, 7 years experience working with African clientele.)

\subsubsection{Working to maintain HIV specific services through the consultant}

While access to care at the level of the GP is possible in most of the cases encountered during data collection, there were substantially different challenges seen when one considers the impact of migration status on the ability of the undocumented to gain the care of consultants. The data reflecting the challenges associated with gaining access to consultant care, as it is in the following passage, revealed an interesting trend. 
What happens unfortunately is that the GM clinic looks the other way, a lot like the GPs. People can go there and get medications, and other treatments. As long as they stay well, that is good. They continue to come in, get treatment, get the things that they need. The real problem comes when they get sick. You see, the care in the clinic is easier to provide regardless of someone's status. The real problem comes when they have to be placed in hospital, you know, for a severe illness. Once someone is placed in hospital, financial officials then begin the process of determining eligibility. As you know, we have laws that require visitors, among others to pay. When they begin to search for this information, the person is generally identified as being illegal, a failed asylum seeker or whatever. The difficult part is, that while they had been very ill, by virtue of the hospitalization, they are suddenly well enough to be deported. This is very difficult, in that the treatment set the stage for the deportation.

The least concrete form of service limitation to undocumented African immigrants living with HIV/AIDS occurs in the case of the GM clinics based within regional hospital facilities. This section focuses on the individual who entered care in one of these facilities while they were legal, and then subsequently lost their legal status. The participants focused on vague instances where they have seen this form of service denial, as in the following statement.

The GUM clinics though are associated with the hospitals, so they are having terrific problems. You know, administrators are not in a position to worry about things like ethics. They are driven by budgets and the need to help the people whose care they are charged with, so it is not in their interest to care for more people than they might already have in the system. (Case Worker, 20 years combined experience as an activist and social care provider for people living with HIV/AIDS.)

\section{Discussion}

The pattern of access to care within the GM clinics was highly inconsistent when considering undocumented African migrant's ability to reliably access services. The data revealed the existence of several vitally important processes: 1) All African migrants are granted access to care at the GM clinics upon arrival to the UK. 2) There is wide agreement on the part of participants that their clients are losing eligibility to receive care at the GM clinics once they have failed on appeal of negative asylum decisions. 3) The GM clinics, regardless of size, have been seen to inconsistently enforce the prohibition on providing care to the undocumented. Factors such as healthcare worker unwillingness to deny care to their previously legal clients were cited repeatedly. 4) There are cases wherein undocumented African migrants who previously had access to GM clinics, have lost their access due to losing their asylum claims on appeal. A prime factor in such cases tended to be associated with hospitalization during acute illness, which resulted in administrators performing eligibility checks. 5) Undocumented migrants were able to maintain access to health services through their GP, however, GPs are not able to provide HIV specific therapy. Thus, undocumented African migrants maintain limited access to healthcare via the GP, and at times when they experience life-threatening illness. Otherwise, they eventually lose the ability to gain treatment with common anti-retroviral therapies.

Figure 1 presents the theoretical model, and provides a graphic depiction of the primary barriers faced by undocumented migrants related to their ability to access services within the NHS. This theoretical model is original to the current study, and was developed based upon the analysis. The data included in this study was not sufficient to develop a broad theory that took into account all of the variables that play a role in limiting access to healthcare services. While substantial information was obtained from providers, an exhaustive list of variables would require data gathering from African migrants as well. Figure 1, however, provides a representation of variables that influence the ability of undocumented African migrants to gain health services. The left column reflects the social processes that act to limit services during the period that individuals enjoy legal status. This element of the diagram also reflects the broad availability of services. Conversely, the right column focuses on the social process that accounts for the greatest limitation to accessing health services; failure of the asylum application. This social process is further complicated by the fact that individuals remain in the country awaiting deportation for a period, and lack access to HIV/AIDS specific services during that period; thus, this segment of the immigrant population is without access to services prior to deportation.

In addition, the data mirrored another finding in the literature that supported the notion of access to health services occurring primarily due to one's status as an asylum seeker. ${ }^{[22]}$ Even in cases where access was available, African migrants tended to receive care later in the process. ${ }^{[23,24]}$ The data of the current study, as well, illustrated trends whereby care 
was sought later in the process. The current study, however, from barriers to the ability of undocumented migrants to went further by attributing non-systemic sociocultural factors such as those represented by fear of stigma as an important factor that tended to delay access to services. The literature $^{[14,15]}$ reflected on the delays in care that have resulted access care. While this phenomenon was present in the data of the current study, the majority of lost access to health services reported by caseworkers was associated with refusal of final immigration appeal resulting in loss of legal status.

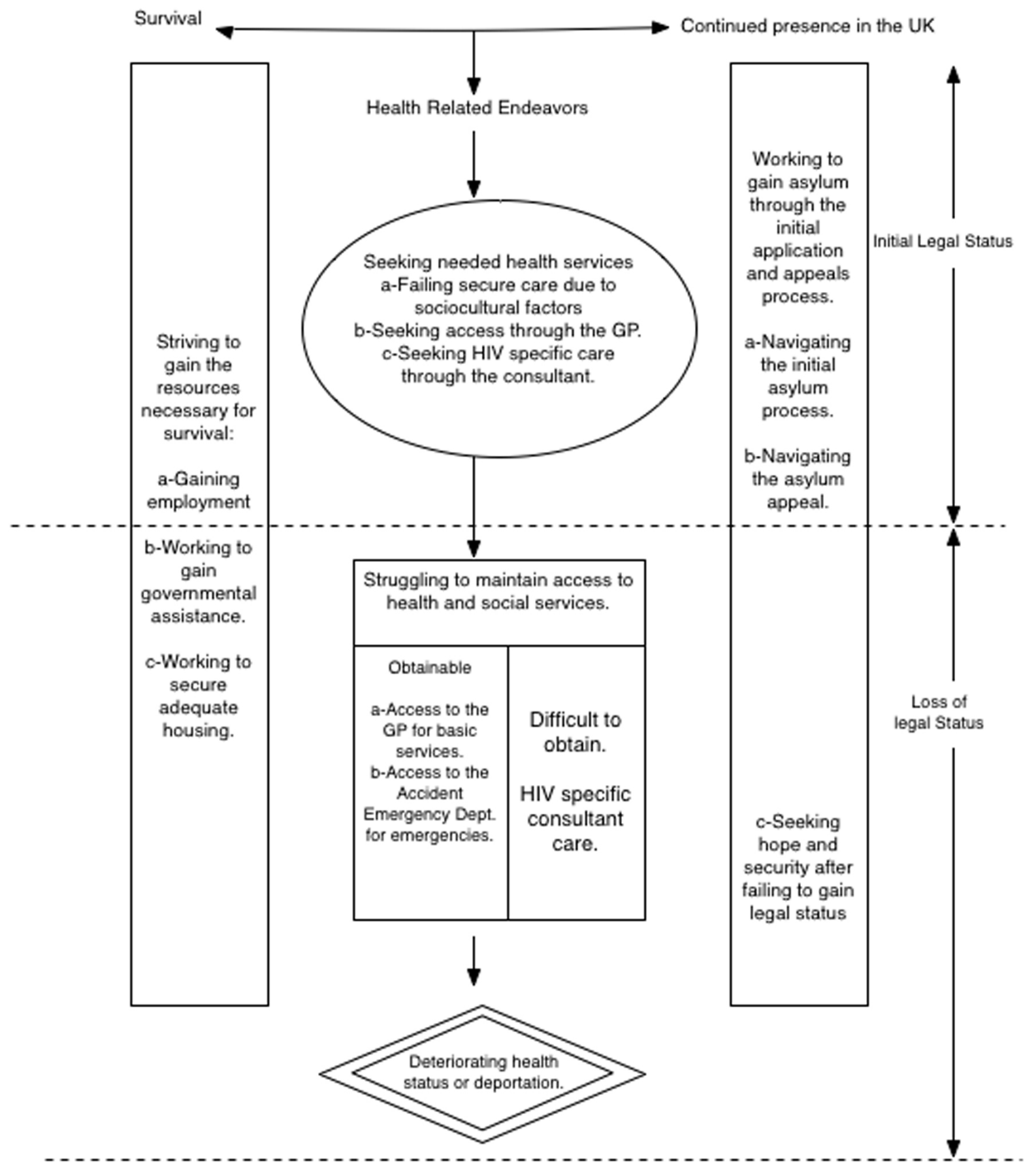

Figure 1. Theoretial model for undocumented African migrants access to health services in the UK

The results of the study were consistent with the literature with regards to overall challenges experienced by undocumented African migrants living with HIV/AIDS. The data re- flected a population who lacked the resources to gain needed services outside of the asylum application and appeal process, and who were persistently afflicted with poverty. ${ }^{[4-6]}$ 
Additionally, the data extended our knowledge of the effect of denial of the asylum application and subsequent loss on appeal. ${ }^{[5,23,24]}$ This involved the near certainty of migrants loss of access to HIV specific care. Ironically, this loss of access often occurred secondary to a severe illness for which they received treatment based upon the legal requirement to offer life-preserving care. The provision of life-preserving care then results in loss of access to chronic therapies that are, similarly, life preserving. The pattern of emerging service denial was consistent with the limited available literature reflecting upon this phenomenon. ${ }^{[25-27]}$

Interestingly, GP based clinics widely continue to offer care after loss on appeal due to GPs who are unwilling to sever their doctor-patient relationship out of an ethical commitment to provide care. Further, individuals maintained eligibility to gain care through Accident-Emergency Departments (although they would be billed for said services) in the case of life threatening illness. The denial of HIV/AIDS specific care virtually guarantees that this will happen, placing an unnecessary burden on the individual and the healthcare system. At the time of discharge, the very individual who was provided life saving care, is again ineligible for services, and thus, is again at risk of re-hospitalization. This inconsistent pattern of access results in suffering to the individual, and greatly taxes the hospitals within the NHS.

All told, the data reflects on the existence of significant barriers to healthcare access. HIV specific care is administered specifically within the GU medicine clinics. These clinics are the sole location wherein HIV specific therapies are available. Most undocumented migrants maintain access to GP based services, however, GPs are unable to address treatment needs specific to HIV. Since African migrants denied asylum are not immediately deported upon their loss on appeal, the result is a period during which they lose their ability to access vital HIV specific care. This lapse in access is life threatening to people living with HIV, since resistance to antiretrovirals is a consequence of interruptions in anti-retroviral therapy. Thus, even if a person is returned to their country of origin, their HIV strain may have grown resistant to common therapies, virtually ensuring their decline. Essentially, African migrants living with HIV who are denied asylum and deported are sent to their home country to die.

The primary limitations of the current study are common to studies of the scale of the current study. First, the sample was limited to three geographical areas of the country, and thus, failed to gain data from the north of England, where services are offered to this community. It was simply not possible to include every region. Secondly, because of limitations to our ability to access participants, we were not able to directly access undocumented migrants. This was due to ethics committee concerns regarding their highly vulnerable status. All told, however, the study is the first of its kind to reflect on the experiences of this population on a national level. In the future, we plan to conduct a more extensive study that includes both the migrants themselves and a broader representation of the country. Additionally, current issues surrounding the British exit from the European Union call for follow on studies that address these issues.

\section{Implications for policy and practice}

The current study reflects a significant public health challenge, especially given that HIV disease has significant implications when considering the possibility of the disease spreading to other populations. This possibility is compounded when people are not receiving treatment, and thus, have a higher probability of transmitting the virus. The study indicates a significant disconnect between the primary care system and the specialty care system. The results is a system where individuals initially receive care at both levels, but then lose access to specialty care, and thus lose their access to treatment. Policy makers have a unique opportunity to address this shortcoming. For instance, simply making it possible for GPs to prescribe anti-retroviral medications to these populations would greatly diminish the impact of a failed asylum application. Even in cases where deportation is the end result, it is essential that individuals receive treatment until they arrive in their country of origin.

\section{Conclusion}

The findings obtained in this study reflected upon a complex representation of the interaction between the basic social processes underlying African migrants' efforts to gain healthcare services. The findings identified a period during which migrants are able to enter the medical care system during arrival, asylum application and appeal. The findings as well, identified an emerging pattern of service denial after loss on immigration appeal, which often resulted in a discontinuation of medical therapies. Following loss of the asylum applications on appeal, many continued to receive care as a result of ethical commitments of GPs and case managers. Events such as hospitalization, however, highlighted an absence of eligibility ultimately leading to subsequent cessation of care and deportation. The results of this study are notable in that they have identified a sequence of events related to the interaction between the asylum process and access to health related services.

\section{CONFlicts of Interest Disclosure}

The authors declares that there is no conflict of interest. 


\section{REFERENCES}

[1] Home Office. Immigration Research and Statistics Office. Control of immigration: Quarterly Statistical Summary, United Kingdom-Third Quarter. 2009. London, England: The Home Office.

[2] Home Office. Population of the UK by country of birth and nationality. London, England: The Home Office. 2017.

[3] Travis A. Migrants amnesty would aid economy by 3 billion, says study. The Guardian Unlimited. 2009.

[4] Lewis H. Still Destitute: A Worsening Problem for Refused Asylum Seekers. London: Joseph Rowntree Charitable Trust. 2009.

[5] Crusaid Hardship Fund. Poverty and HIV. London: Crusaid Hardship Fund. 2011.

[6] Refugee Survival Trust and British Red Cross. 21 Days Later: Destitution and the asylum system. London: Refugee Survival Trust. 2007.

[7] Refugee Council. Hungry and homeless: The impact of the withdrawal of state support on asylum seekers, refugee communities and the voluntary sector. London: Refugee Council. 2004.

[8] Refugee Council. A study of asylum seekers with special needs. London: Refugee Council, London. 2005.

[9] Chauvin P, Parizot I, Simonnot N. Access to healthcare for undocumented migrants in 11 European Countries. Paris: Medicins Du Monde. 2008.

[10] Yates T, Crane R, Burnett A. Rights and the reality of healthcare charging in the United Kingdom. Medicine, Conflict \& Survival. 2007; 23: 297-304. PMid:17987981 https ://doi.org/10.1080/ 13623690701596775

[11] Harris R. The Exclusion of Failed Asylum Seekers from Free NHS Care: A Policy Analysis and Impact Assessment. International Health and Medical Education Centre, University College of London. 2005.

[12] Hargreaves S, Frieland J, Gothard P, et al. Impact on and use of health services by international migrants: Questionnaire survey. 2006.

[13] Kelley N, Stevenson J. First Do No Harm: Denying Healthcare to People Whose Asylum Claims Have Failed. London: Oxfam Refugee Council. 2006.

[14] Penrose J. Poverty and asylum in the UK. London: Oxfam; 2002.

[15] Burns F, Imrie J, Nazroo J, et al. Why they wait? Key informant understandings of factors contributing to late presentation and poor utilization of HIV health and social services by African mi- grants in Britain. AIDS Care. 2007; 19: 102-108. PMid:17129864 https://doi.org/10.1080/09540120600908440

[16] Boyd A, Murad S, O'Shea S, et al. Ethnic differences in the stage of presentation of adults newly diagnosed with HIV infection in south London. HIV Medicine. 2005; 6: 59-65. PMid:15807711 https://doi.org/10.1111/j.1468-1293.2005.00267.x

[17] Chadborn T, Delpech V, Sabin C, et al. The late diagnosis and consequent short-term mortality of HIV infected heterosexuals (England \& Wales, 2000-2004). AIDS. 2006; 20: 2371-2379. PMid:17117024 https://doi.org/10.1097/QAD.0b013e32801138f7

[18] Glaser B. Conceptualization: On theory and theorizing using grounded theory. International Journal of Qualitative Methods. 2002; 2: 23-38. https://doi.org/10.1177/160940690200100203

[19] Stern P. On solid ground: Essential properties for growing grounded theory. From Bryant, A. and Charmaz, K. The Sage Handbook of Grounded theory. Sage Publications. 2008.

[20] Seaman J. Adopting a grounded theory approach to cultural-historical research: Conflicting methodologies or complementary methods. International Journal of Qualitative Methods. 2008; 7(1): 8-11.

[21] Glaser B. Basics of grounded theory analysis: emergence versus forcing. Mill Valley, Ca: Sociology Press; 1992.

[22] Cooke G, Hargreaves S, Natkunarajah J, et al. Impact on and use of an inner-city London infectious diseases department by international migrants: a questionnaire survey. BMC Health Services Research 2007; 113: 1-7.

[23] Erwin J, Morgan M, Britten N, et al. Pathways to HIV testing and care by black African and white patients in London. Sexually Transmitted Infections. 2002; 78: 37-39. https ://doi.org/10.1136/ sti.78.1.37

[24] O'Farrell N, Lau R, Yoganathan K, et al. AIDS in Africans living in London. Genitourinary Medicine. 2005; 71: 358-362.

[25] Gazzard B, Anderson J, Ainsworth J, et al. Treat with respect: HIV, public health and immigration. London: All Party Parliamentary Group on AIDS. of inner city London A\&E attenders. BMC Health Services Research. 2005; 6: 1-7.

[26] Power L, Azad Y, Fortier E. Campaign on Access to HIV Services for all Migrants to the UK. London: Terrence Higgins Trust. 2004.

[27] Reeves M, de wilt G, Murshalie H, et al. Access to healthcare for people seeking asylum in the UK. British Journal of General Practice. 2006; 56: 306-308. 